\title{
Correlates of intimate partner violence against women during a time of rapid social transition in Rwanda: analysis of the 2005 and 2010 demographic and health surveys
}

Dana R. Thomson ${ }^{1,2}$, Assiatou B. Bah², Wilson G. Rubanzana ${ }^{1,3}$ and Leon Mutesa ${ }^{4 *}$

\begin{abstract}
Background: In Rwanda, women who self-reported in household surveys ever experiencing intimate partner violence (IPV) increased from $34 \%$ in 2005 to 56 \% in 2010. This coincided with a new constitution and majorityfemale elected parliament in 2003, and 2008 legislation protecting against gender-based violence. The increase in self-reported IPV may reflect improved social power for women, and/or disruptions to traditional gender roles that increased actual IPV.
\end{abstract}

Methods: This is a cross-sectional study of IPV in 4338 couples interviewed in the 2005 and 2010 Rwanda Demographic and Health Surveys (RDHSs). Factors associated with physical or sexual IPV in the last 12 months were modeled using manual backward stepwise logistic regression. Analyses were conducted in Stata v13 adjusting for complex survey design.

Results: Risk factors for IPV in 2005 ( $p<0.05)$ were: experiencing emotional IPV $(O R=18.1)$, beating husband/partner unprovoked ( $\mathrm{OR}=12.3)$, witnessing IPV against mother $(\mathrm{OR}=1.82)$, husband/partner consumes alcohol often $(\mathrm{OR}=3.13)$, and polygynous marriage $(\mathrm{OR}=1.51)$, whereas having a husband/partner with secondary education $(\mathrm{OR}=0.43)$ was protective. Factors associated with increased IPV in $2010(p<0.05)$ were husband/partner $(\mathrm{OR}=1.30)$ or woman $(\mathrm{OR}=1.36)$ believes IPV is justified, husband/partner has sex with non-marital partners $(\mathrm{OR}=2.52)$, bottom wealth quintile $(\mathrm{OR}=1.25)$, polygynous marriage $(\mathrm{OR}=2.29)$, having a son $(\mathrm{OR}=2.05)$ or only daughters $(\mathrm{OR}=2.58)$ versus no children, and having a husband/partner employed with in-kind versus cash compensation (OR =1.58). In 2010, woman being involved with her own health $(O R=0.79)$ or earnings $(O R=0.57)$ decision-making was protective against IPV. Several variables were not available in the 2010 RDHS.

Conclusions: Our results may provide evidence of both increased self-reporting of IPV and social power disruption. Rwanda's Isange One Stop Center project, with medical, legal, and psychosocial services for domestic violence victims, is currently scaling to all 44 district hospitals, and police station gender desks reduce barriers to legal reporting of IPV. Additional support to Abunzi mediators to hear IPV cases in communities, and involvement of men in grassroots efforts to redefine masculinity in Rwanda are suggested. Additional research is needed to understand why self-reported IPV has increased in Rwanda, and to evaluate effectiveness of IPV interventions.

Keywords: Violence against women, Gender based violence, Domestic violence, IPV, GBV, DHS, Africa, Physical, Sexual

\footnotetext{
* Correspondence: I.mutesa@ur.ac.rw

${ }^{4}$ College of Medicine and Health Sciences, University of Rwanda, PO Box 945, Kigali, Rwanda

Full list of author information is available at the end of the article
}

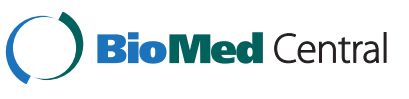

(c) 2016 Thomson et al. Open Access This article is distributed under the terms of the Creative Commons Attribution 4.0 International License (http://creativecommons.org/licenses/by/4.0/), which permits unrestricted use, distribution, and reproduction in any medium, provided you give appropriate credit to the original author(s) and the source, provide a link to the Creative Commons license, and indicate if changes were made. The Creative Commons Public Domain Dedication waiver (http://creativecommons.org/publicdomain/zero/1.0/) applies to the data made available in this article, unless otherwise stated. 


\section{Background}

Intimate partner violence (IPV) describes physical, sexual, or psychological harm by a current or past partner. Not only does IPV compromise survivors' basic human rights, physical and sexual assault can result in direct physical harm, sexually transmitted infections, or pregnancy, and all IPV can result in long-term mental and physical health problems $[1,2]$. While IPV occurs in heterosexual and same-sex couples and is perpetrated by both women and men, the majority of cases are perpetrated by male partners against female partners worldwide [3]. A World Health Organization (WHO) analysis combining data from 77 studies across 56 countries estimated that, in Africa, 37 \% of women have ever experienced physical or sexual IPV [3]. These rates were similar to the Eastern Mediterranean (37 \%) and SouthEast Asia (38\%), and higher than the Americas (30\%), Europe (25\%), and Western Pacific (25\%) [3].

Within region and country, however, experiences of IPV vary widely, underscoring differences in national histories, institutional policies, cultural identities, resources, and other factors. When comparable measures and methods are used to measure lifetime prevalence of physical and sexual violence across national surveys [4-7], they show that lifetime prevalence of physical or sexual violence ranges from $64 \%$ in Democratic Republic of Congo and Bolivia, to $6 \%$ in Canada [3]. In national surveys, physical violence includes such actions as being beat, hit, kicked, choked, burned, or threatened with a weapon. Sexual violence is defined as being physically forced or threatened to have sex or to do something sexually degrading. Two such national surveys in Rwanda found that a woman's experience of physical or sexual IPV in her lifetime almost doubled from $34 \%$ in 2005 [8] to $56 \%$ in 2010 [9] placing Rwanda among the countries with the high rates of IPV against women in the world.

Rwanda is a small, densely populated country that has undergone rapid demographic, social, and economic transition in the last 20 years since the Tutsi Genocide that killed around 1 million people. In the period between 2005 and 2010, fertility rates fell from 6.1 to 4.6 children per woman, child mortality was halved from 152 to 76 deaths per 1000 live births, and the percent of women completing secondary school increased from 1.6 to $4.3 \%[8,9]$. Meanwhile, representation of women in parliament has increased dramatically from $18 \%$ before the Genocide, to $26 \%$ during the post-genocidal transitional government (1994-2003), to $56 \%$ in the 2008 elections when Rwanda became the first and only country in the world with a majority woman parliament.

Women's political representation and legal protection is an important step toward gender equity. Several factors may contribute to women's political representation in Rwanda; foremost, Rwanda's government has prioritized women's political inclusion. In 2003, new legislation reserved 24 of 80 parliamentary seats for women-only parliamentarians to be filled by women-only voters [10]. While the evidence is mixed about whether more women representation changes policy outcomes overall [10], key pieces of legislation in Rwanda have certainly been shaped and shepherded by women parliamentarians including the 2008 law (No. 59/2008) on Prevention and Punishment of Gender-Based Violence (GBV). Some have suggested that Rwanda's population, which is currently comprised of more women than men as a result of men being targeted during the genocide, has contributed to women's political representation [10], as well as additional leadership roles by women within households [11]. Many assume that these gains in women's representation and protections reflect women's empowerment, which makes the dramatic rise in self-reported IPV against women between 2005 and 2010 particularly striking.

Violence in intimate partnerships is a common phenomenon worldwide, and is partially attributed to couples spending lots of time with each other [12]. Time exposure, however, does not explain why women and not men are most often the target of IPV. Feminist and socio-culture explanations provide frameworks to understand IPV against women. Power theory explains increases in IPV that coincide with women's empowerment as a result of disruptions in traditional gendered roles [13]. Social learning theory adds that violence against women is learned through witness of IPV against women in childhood, and early experiences that cement these 'lessons' [14]. Background/situation modeling builds on this by adding that historical and socio-cultural context further normalizes violence in relationships [14].

In Africa, systematic gender inequality is often reinforced by cultural traditions of men in roles of head of household in charge of family finances and decisions [12], as well as colonial and post-colonial histories of slavery and labor migration that resulted in the absence of adult men and the feminization of poverty within households [13]. Until discussion of the new Inheritance Law began 1998, Rwandan land ownership and inheritance law treated women like minors; a spouse or father could appropriate a woman-owned business, and it was not acceptable for a woman to speak and share her own views in public (only on behalf of her family) [14]. The near universal exposure of adults to community violence during the genocide may exacerbate any existing ideas of normalized IPV. Finally, Rwanda faces the same male-female power differentials in the media as other countries [15]. Popular media worldwide portrays sexism, devaluation of women, and direct violence against women [16], which is reinforced locally by dominant community perceptions of gender differences $[15,17]$. 
Adding household-level triggers for violence such as financial stress or alcohol abuse can further increase risk of IPV $[14,15]$.

Gender roles in Rwanda are in the midst of rapid transition, and the implications for IPV are not well understood. In a qualitative study in Rwanda after 2003, women described experiencing greater respect by family and community members, new confidence to speak in public forums, more autonomy and opportunities, as well as increased friction with their brothers and husbands, perceptions that men were withdrawing from politics, and feelings that the institution of marriage had been disrupted due to rapid changes in conventional gender roles [18]. A 2010 qualitative study on the same topic found that laws protecting women's rights were perceived by women and men as having led to loss of women's values and respect for men, thus provoking husbands to resort to violence to re-establish order in their households; this type of violence is believed by many woman and men as normal and even necessary $[19,20]$. The large increase in self-reported IPV between 2005 and 2010 may reflect greater empowerment of women to speak about a high level of violence that already existed, or it could reflect a real increase in experiences of IPV. The present paper identifies factors associated with physical or sexual IPV in Rwanda in 2005 and 2010 that might inform hypotheses and further research about IPV against women in Rwanda.

\section{Methods}

Data

This analysis is based to the 2005 and 2010 Rwanda Demographic and Health Surveys (DHSs), which are nationally and sub-nationally representative two-stage cluster samples, conducted every 5 years to monitor demographic, socioeconomic, and health indicators [8]. In both surveys, primary sampling units (PSUs) were randomly selected from a recent census listing, and urban PSUs were oversampled to increase precision of urban estimates. Questionnaires were translated into Kinyarwanda, back translated into English, and field tested before implementation. Women aged 15 to 49 were the primary respondents, answering detailed questions about themselves, their households, and their children. Men aged 15 to 59 were secondary respondents, selected from every 3rd household in 2005, and every 2nd household in 2010. Both surveys were implemented by the National Institute of Statistics-Rwanda with technical support from Macro International, Inc. and funding from USAID, and in both surveys the all-female interviewing teams received the same standardized training $[8,9]$.

Of the 11,321 and 13,671 women interviewed in 2005 and 2010, respectively, 4066 and 5008 were randomly selected and agreed to complete a special module about domestic violence. Only one woman per household was selected for the domestic violence module to ensure that no one else in the household knew about sensitive questions that could compromise her safety, and to minimize the total number of women asked to describe traumatic events. Female interviewers received special training to conduct secure, confidential interviews in respondents' homes and administered the domestic violence module in face-to-face interviews; they were supposed to skip the module if a confidential interviewing environment was not possible. According to the DHS datasets, $100 \%$ of women in 2005 and more than $99 \%$ of women in 2010 who were selected for the domestic violence module completed it. Of the 9074 women interviewed across the two surveys, 4338 had husbands/partners who were interviewed in the men's survey. In this analysis of 4338 couples (2005: 1888; 2010: 2450), we link women's selfreports of intimate partner violence in the last 12 months with husband/partner's survey responses based on wifeID in the men's questionnaire.

In the domestic violence module, women were asked directly about their experiences of physical and sexual violence in the last 12 months and this outcome was modeled as a binary variable. In the 2005 survey only, women reported emotional IPV, physical violence perpetrated against her husband/partner when he was not already physically hurting her, history of her father beating her mother, and frequency of husband/partner's alcohol usage, all of which are key risk factors for IPV against women $[14,21-25]$. In both years, men and women were asked about their own demographic, education, and employment characteristics, as well as their perceptions of violence against women, and who makes decisions about their own health care and earnings. An adult in the household answered an additional questionnaire about household assets, and demographics of each household member including their age, sex, and household membership.

\section{Ethics}

Both the 2005 and 2010 DHSs were reviewed and approved by the Macro International Internal Review Board, Rwanda's National Institute of Statistics, and the National Ethics Committee of Rwanda. We were granted permission by Macro International, Inc. to use these deidentified data for this analysis.

\section{Data analysis}

We used multivariable regression to identify belief or behavioral and socio-demographic factors associated with sexual or physical IPV against women in Rwanda in 2005 and 2010. We used percentages and Chi-square tests to compare $(p<0.05)$ socio-demographic characteristics of women in this study with married/partnered 
women not in the study (because their partner was not interviewed) and divorced or separated women. Then we defined 25 potential covariates and tested bivariate Chisquare distributions among women who had, and had not, experienced physical or sexual IPV in the last 12 months. Non-collinear (Pearson correlation $r<0.5$ ) variables associated with IPV (at $p<0.1$ ) were retained for multivariable model building. Finally, we used manual backward stepwise logistic regression, first removing variables that were least associated with IPV and retaining those variables that were associated with IPV $(p<0.05)$. Separate models were fit for 2005 , for 2005 using the reduced set of variables available in 2010, and for 2010. The analysis was carried out in Stata version 13 using survey commands to apply sampling probability weights, account for clustering and stratification in the sample design, and perform subpopulation analysis in couples only. We presented final models as odds ratios (ORs) with $95 \%$ confidence intervals.

\section{Results}

Self-reported IPV in the last 12 months among married/ partnered women doubled from $24.1 \%$ to $49.5 \%$ between 2005 and 2010. In 2005 and 2010, the married/ partnered women in our study were slightly younger, less educated, and less likely to work than women whose husbands/partners were not interviewed or who were divorced or separated $(p<0.05$ for all) (Table 1$)$. There was a sizable increase in the percent of women who say a man is justified to beat his wife for at least one reason from $46.5 \%$ in 2005 to $57.0 \%$ in 2010 (Table 1).

In bivariate analysis in 2005, sexual or physical IPV was associated with emotional IPV (84.7 \%), witnessing physical violence by father against mother as a child (31.5\%), and having a partner who consumes alcohol often $(54.3 \%)(p<0.001$ for all) (Table 2). IPV was also high in relationships where the wife reported beating her husband/partner when he was not already hurting her $(82.4 \%, p<0.001)$, though only nine women $(<1 \%)$ reported this behavior. No other beliefs or behaviors were associated with IPV in 2005. A number of sociodemographic factors were associated with IPV in 2005 $(p<0.1)$ including rural residence, polygynous marriage, having any children, there being no adults other than the couple in the household, having a husband/partner with less than secondary education, and the woman having less than secondary education.

In 2010, many of the same socio-demographic factors were associated with IPV, however, a number of beliefs and behaviors were newly associated with IPV $(p<0.1)$ including partner believes a man can beat his wife, woman believes a man can beat his wife, woman is not involved with her own health decision-making, woman is not involved with decision-making about her earnings, husband/partner has sex with non-wife partner(s), and the woman says she cannot refuse sex with her partner or request use of a condom.

In the 2005 multivariable analysis, two factors stand out as being strongly associated with IPV (Table 3). Women who experienced emotional IPV in the last year had 18 times the odds $(p<0.001)$ of sexual or physical IPV, and women who reported beating their husband/ partner unprovoked had 12 times the odds $(p<0.01)$ of sexual or physical IPV. Having a partner that consumes alcohol very often $(\mathrm{OR}=3.13, p<0.001)$, witnessing physical IPV against her mother in childhood $(\mathrm{OR}=$ 1.82, $p<0.001)$, and being in a polygynous marriage $(\mathrm{OR}=1.51, p<0.05)$ were also associated with increased odds of sexual or physical IPV. Women who had a partner with secondary or higher education had lower odds of IPV (OR $=0.43, p<0.01)$. When emotional violence, woman beats husband/partner unprovoked, woman witnessed IPV against mother in childhood, and husband/ partner consumes alcohol often were removed from the model to make it comparable to the 2010 analysis, two additional demographic characteristics were associated with IPV: women's primary education versus no education $(\mathrm{OR}=1.40, p<0.05)$, and woman has at least one son $(\mathrm{OR}=2.04, p<0.05)$ or daughters only $(\mathrm{OR}=2.11$, $p<0.05)$ versus no children.

Several beliefs and behaviors that were not associated with IPV in 2005 were significant in the 2010 multivariate analysis. Partner believes a man is justified to beat his wife $(\mathrm{OR}=1.30, p<0.05)$, woman believes a man is justified to beat his wife $(\mathrm{OR}=1.36, p<0.05)$, and partner has sex with non-wife partner(s) $(\mathrm{OR}=2.52, p<$ 0.001) were all associated with greater odds of IPV. Furthermore, woman being involved with decisions about her own health $(\mathrm{OR}=0.79, p<0.05)$ or about her own earnings $(\mathrm{OR}=0.57, p<0.05)$ versus her partner alone were protective against IPV. Being a household in the bottom wealth quintile $(\mathrm{OR}=1.25, p<0.05)$, being in a polygynous marriage $(\mathrm{OR}=2.29, p<0.01)$, having a son $(\mathrm{OR}=2.05, p<0.01)$ or only daughters $(\mathrm{OR}=2.58, p<$ 0.001 ) versus no children, and having a partner employed with in-kind versus cash earnings $(\mathrm{OR}=1.58$, $p<0.001$ ) were associated with greater odds of IPV.

\section{Discussion}

Physical or sexual intimate partner violence (IPV) selfreported in household surveys doubled between 2005 and 2010 which coincided with a rise in the percent of women who say that IPV is justified from $46.7 \%$ to $57.0 \%$. In 2010, nearly half of all partnered women experienced physical or sexual IPV in the previous 12 months, and IPV tended to occur in tandem with multiple other forms of violence. Our 2005 finding that women who experienced emotional violence [26], who 
Table 1 Distribution of key women socioeconomic characteristics and beliefs by marital status and inclusion criteria

\begin{tabular}{|c|c|c|c|c|c|c|}
\hline & \multicolumn{3}{|c|}{ Interviewed about domestic violence } & \multirow[b]{3}{*}{$\begin{array}{l}x^{2} \\
p \text {-value }\end{array}$} & \multirow[b]{3}{*}{$\begin{array}{l}\% \\
\text { Widowed }\end{array}$} & \multirow[b]{3}{*}{$\begin{array}{l}\% \text { Never in } \\
\text { union }\end{array}$} \\
\hline & Included & & & & & \\
\hline & $\begin{array}{l}\% \text { In union, partner } \\
\text { interviewed }\end{array}$ & $\begin{array}{l}\% \text { In union, partner } \\
\text { not interviewed }\end{array}$ & $\begin{array}{l}\% \text { Divorced, } \\
\text { separated }\end{array}$ & & & \\
\hline \multicolumn{7}{|l|}{2005} \\
\hline Woman's age & & & & $<0.001$ & & \\
\hline $15-19$ & 1.1 & 0.1 & 0.7 & & 0.0 & 60.0 \\
\hline $20-29$ & 39.9 & 30.9 & 30.5 & & 3.0 & 33.7 \\
\hline $30-39$ & 35.4 & 38.1 & 32.5 & & 27.4 & 4.6 \\
\hline $40-49$ & 23.5 & 30.9 & 36.4 & & 69.5 & 1.6 \\
\hline Woman's education & & & & 0.014 & & \\
\hline No school & 28.3 & 34.1 & 34.1 & & 40.6 & 8.6 \\
\hline Primary & 64.0 & 55.5 & 60.0 & & 46.3 & 78.7 \\
\hline Secondary or higher & 7.7 & 10.4 & 5.9 & & 13.1 & 12.7 \\
\hline Woman's employment & & & & 0.033 & & \\
\hline Employed, for cash & 17.0 & 18.0 & 24.7 & & 24.9 & 19.6 \\
\hline Employed, in - kind & 50.0 & 51.4 & 46.2 & & 42.9 & 26.2 \\
\hline Not working & 33.0 & 30.7 & 29.1 & & 32.2 & 54.2 \\
\hline Household wealth & & & & 0.103 & & \\
\hline Top 4 quintiles & 79.6 & 76.2 & 74.5 & & 71.2 & 80.9 \\
\hline Bottom quintile & 20.4 & 23.8 & 25.5 & & 28.8 & 19.1 \\
\hline Household residence & & & & 0.013 & & \\
\hline Urban & 12.0 & 14.6 & 17.6 & & 19.9 & 21.6 \\
\hline Rural & 88.0 & 85.4 & 82.4 & & 80.1 & 78.4 \\
\hline $\begin{array}{l}\text { Woman believes a man can beat his } \\
\text { wife }\end{array}$ & & & & 0.822 & & \\
\hline 0 reasons & 53.5 & 51.7 & 52.2 & & 57.2 & 52.9 \\
\hline $1+$ reasons & 46.5 & 48.3 & 47.8 & & 42.8 & 47.1 \\
\hline Total & 100.0 & 100.0 & 100.0 & & 100.0 & 100.0 \\
\hline$N$ (unweighted) & 1888 & 448 & 378 & & 157 & 1195 \\
\hline \multicolumn{7}{|l|}{2010} \\
\hline Woman's age & & & & $<0.001$ & & \\
\hline $15-19$ & 1.4 & 1.4 & 3.0 & & 0.0 & 54.5 \\
\hline $20-29$ & 42.5 & 30.0 & 30.4 & & 5.2 & 39.7 \\
\hline $30-39$ & 36.0 & 38.5 & 35.8 & & 21.0 & 4.5 \\
\hline $40-49$ & 20.1 & 30.1 & 30.8 & & 73.8 & 1.3 \\
\hline Woman's education & & & & 0.054 & & \\
\hline No school & 19.4 & 19.4 & 27.3 & & 36.4 & 6.1 \\
\hline Primary & 71.2 & 68.6 & 64.4 & & 53.3 & 66.4 \\
\hline Secondary or higher & 9.4 & 12.1 & 8.4 & & 10.3 & 27.5 \\
\hline Woman's employment & & & & 0.005 & & \\
\hline Employed, for cash & 56.9 & 52.8 & 65.9 & & 60.5 & 34.6 \\
\hline Employed, in - kind & 22.7 & 28.3 & 16.2 & & 18.8 & 23.6 \\
\hline Not working & 20.4 & 18.9 & 18.0 & & 20.8 & 41.8 \\
\hline
\end{tabular}


Table 1 Distribution of key women socioeconomic characteristics and beliefs by marital status and inclusion criteria (Continued)

\begin{tabular}{|c|c|c|c|c|c|}
\hline \multicolumn{4}{|l|}{ Household wealth } & \multicolumn{2}{|c|}{$<0.001$} \\
\hline Top 4 quintiles & 82.5 & 74.3 & 68.7 & 74.2 & 86.2 \\
\hline Bottom quintile & 17.5 & 25.7 & 31.3 & 25.8 & 13.8 \\
\hline \multicolumn{4}{|l|}{ Household residence } & \multicolumn{2}{|c|}{0.697} \\
\hline Urban & 12.7 & 13.7 & 14.4 & 17.7 & 18.3 \\
\hline Rural & 87.3 & 86.3 & 85.6 & 82.3 & 81.7 \\
\hline \multicolumn{4}{|c|}{$\begin{array}{l}\text { Woman believes a man can } \\
\text { beat his wife }\end{array}$} & \multicolumn{2}{|c|}{0.165} \\
\hline 0 reasons & 43.0 & 43.8 & 36.7 & 43.4 & 47.7 \\
\hline $1+$ reasons & 57.0 & 56.2 & 63.3 & 56.6 & 52.3 \\
\hline Total & 100.0 & 100.0 & 100.0 & 100.0 & 100.0 \\
\hline$N$ (unweighted) & 2450 & 493 & 269 & 264 & 1532 \\
\hline
\end{tabular}

witnessed IPV as a child [21-24], or who were violent toward their husband/partner [26] were more likely to self-report IPV in the last year is consistent with other studies. The huge differential in experience of IPV among women versus male partners in 2005 suggests that violence against women is normalized. This is supported by surveys from around the world that find a high proportion of women and men believe that IPV against women is justified $[17,25]$. We discuss two potential hypotheses for the sharp rise in self-reported IPV in Rwanda, and ways that individuals and communities might address IPV against women. Since women in this study were somewhat different from other partnered women, particularly divorced or separated women, caution should be used when generalizing these results.

\section{Individuals and couples}

In our study, IPV was associated with high alcohol usage by husbands/partners, which is consistent with findings from diverse settings including Brazil, Kenya, and India [24, 27-29]. Other studies found that both woman's and men's alcohol usage was an important factor for IPV $[22,24]$. Alcohol use directly affects cognitive and physical function, reducing self-control and leaving individuals less capable of negotiating a non-violent resolution to conflicts within relationships [30]. Excessive drinking by one partner can exacerbate financial difficulties, child abuse, infidelity or other stressful situations, which may fuel conflicts between partners. Because alcohol dependency is linked to numerous health and social problems for drinkers, their families, and communities [31], alcohol dependency is estimated to account for $4 \%$ of global disability adjusted life years (DALYs) [32]. Responsible drinking campaigns, alcohol advertising bans, drinking and driving laws, and increased pricing of alcohol can be implemented by governments to deter drinking, and training of health, social, and legal professionals to support individuals who seek alcohol treatment can help to address IPV risk within couples [31].

Our 2010 finding that IPV was associated with husbands/partners who earned in-kind rather than cash compensation may provide evidence of social power disruptions within relationships as a source of increased incidence of IPV in Rwanda. In-kind rather than cash compensation may be related to the husband/partner having low education [21, 22, 33] which limits income potential, job security, and contributes to financial stress at home, a trigger for violence [28], whereas men who attend secondary school are typically exposed to ideas of human rights and gain skills for self-expression, which can reduce tolerance of IPV $[28,34]$. In Rwanda, men have traditionally been heads of household, the primary cash earners, and decision-makers about household resources, however this has changed rapidly in recent years. Qualitative research about the impacts of Rwanda's improved opportunities for women found that, in addition to numerous positive outcomes, non-submissive, independent women experienced increased conflict within their relationships when husbands felt their own roles were challenged or that their wives where skirting home responsibilities [18]. In India, South Africa, and elsewhere, increases in IPV have been linked with rapid changes in gender roles, including changes in husband/partner employment [31, 35]. In these settings, involvement of men in redefining masculinity has been important toward shifting public opinion about IPV and reducing incidence of IPV $[34,36]$. The rise in reported acceptance of IPV among women in Rwanda suggests that women, too, are in need of involvement and support to redefine gender roles.

Certain family dynamics such as polygynous marriage and having children are slow to change in response to women's changing roles in society, and it is therefore not surprising that these two factors remained significantly 
Table 2 Bivariate associations of physical or sexual IPV in the last 12 months with behavioral and socio-demographic characteristics

\begin{tabular}{|c|c|c|c|c|c|c|c|c|c|}
\hline & \multicolumn{4}{|l|}{2005} & \multicolumn{4}{|l|}{2010} & \multirow{2}{*}{$\begin{array}{l}\text { Source } \\
\text { Questionnaire }\end{array}$} \\
\hline & $\begin{array}{l}\text { (weighted) }\end{array}$ & $\begin{array}{l}\% \\
\text { IPV }\end{array}$ & $95 \% \mathrm{Cl}$ & $\begin{array}{l}X^{2} \\
p \text {-value }\end{array}$ & $\begin{array}{l}N \\
\text { (weighted) }\end{array}$ & $\begin{array}{l}\% \\
\text { IPV }\end{array}$ & $95 \% \mathrm{Cl}$ & $\begin{array}{l}X^{2} \\
p \text {-value }\end{array}$ & \\
\hline \multicolumn{10}{|l|}{ Beliefs and behaviors } \\
\hline Emotional violence by partner last 12 months & & & & $<0.001$ & & & & & Women \\
\hline No & 1432 & 19.4 & {$[17.4,21.5]$} & & Not & & & & \\
\hline Yes & 105 & 84.7 & {$[76.4,90.5]$} & & available & & & & \\
\hline Woman beat partner unprovoked last 12 months & & & & $<0.001$ & & & & & Women \\
\hline No & 1535 & 23.7 & {$[21.6,25.9]$} & & Not & & & & \\
\hline Yes & 9 & 82.4 & {$[49.0,95.8]$} & & available & & & & \\
\hline Woman's father beat mother & & & & $<0.001$ & & & & & Women \\
\hline No & 1028 & 20.4 & {$[18.1,23.0]$} & & Not & & & & \\
\hline Yes & 507 & 31.5 & {$[27.4,35.8]$} & & available & & & & \\
\hline Partner consumes alcohol very often & & & & $<0.001$ & & & & & Women \\
\hline Never or sometimes & 1358 & 19.8 & {$[17.8,21.9]$} & & Not & & & & \\
\hline Very often & 184 & 54.3 & {$[46.5,61.8]$} & & available & & & & \\
\hline Partner believes a man can beat his wife & & & & 0.188 & & & & 0.003 & Men \\
\hline 0 reasons & 1196 & 23.2 & {$[21.0,25.7]$} & & 1638 & 47.9 & {$[45.2,50.5]$} & & \\
\hline $1+$ reasons & 347 & 26.9 & {$[22.2,32.3]$} & & 407 & 56.1 & {$[51.5,60.6]$} & & \\
\hline Woman believes a man can beat his wife & & & & 0.108 & & & & $<0.001$ & Women \\
\hline 0 reasons & 828 & 22.5 & {$[19.8,25.4]$} & & 879 & 43.7 & {$[40.4,47.0]$} & & \\
\hline $1+$ reasons & 718 & 25.9 & {$[22.9,29.2]$} & & 1165 & 54.0 & {$[50.9,57.0]$} & & \\
\hline Woman involved in her own health decisions & & & & 0.134 & & & & $<0.001$ & Women \\
\hline Partner only, other & 654 & 26.1 & {$[22.8,29.7]$} & & 553 & 56.6 & {$[52.0,61.0]$} & & \\
\hline Woman involved & 892 & 22.6 & {$[19.9,25.6]$} & & 1494 & 46.9 & {$[44.4,49.5]$} & & \\
\hline Woman involved with decisions about her earnings & & & & 0.249 & & & & $<0.001$ & Women \\
\hline Partner only, other & 65 & 32.5 & {$[23.5,43.0]$} & & 224 & 64.8 & {$[58.0,71.1]$} & & \\
\hline Woman involved & 217 & 26.1 & {$[20.3,32.8]$} & & 1079 & 48.3 & {$[45.2,51.3]$} & & \\
\hline No earnings & 913 & 22.7 & {$[20.0,25.6]$} & & 534 & 45.0 & {$[40.7,49.4]$} & & \\
\hline Not working & 347 & 24.8 & {$[20.4,29.7]$} & & 206 & 51.4 & {$[44.9,57.9]$} & & \\
\hline Partner had sex with non-wife last 12 months & & & & 0.552 & & & & $<0.001$ & Men \\
\hline No & 1468 & 24.0 & {$[21.8,26.2]$} & & 1971 & 48.7 & {$[46.4,51.1]$} & & \\
\hline Yes & 78 & 26.7 & {$[18.5,36.8]$} & & 75 & 71.0 & {$[60.9,79.3]$} & & \\
\hline Woman says it is okay to refuse sex & & & & 0.709 & & & & 0.008 & Women \\
\hline No & 485 & 24.7 & {$[21.2,28.5]$} & & 445 & 55.4 & {$[50.3,60.3]$} & & \\
\hline Yes & 1059 & 23.8 & {$[21.2,26.6]$} & & 1600 & 47.9 & {$[45.4,50.4]$} & & \\
\hline Woman says it is okay to request use of condom & & & & 0.927 & & & & 0.008 & Women \\
\hline No & 848 & 24.0 & {$[21.1,27.2]$} & & 445 & 55.4 & {$[50.3,60.3]$} & & \\
\hline Yes & 695 & 24.2 & {$[21.1,27.6]$} & & 1600 & 47.9 & {$[45.4,50.4]$} & & \\
\hline \multicolumn{10}{|l|}{ Socio-demographics } \\
\hline Woman's age & & & & 0.739 & & & & 0.091 & Women \\
\hline $15-19$ & 18 & 18.7 & {$[7.5,39.7]$} & & 29 & 29.9 & {$[17.3,46.4]$} & & \\
\hline $20-29$ & 620 & 25.4 & {$[22.3,28.8]$} & & 870 & 48.0 & {$[45.0,51.0]$} & & \\
\hline $30-39$ & 547 & 23.4 & {$[20.3,26.7]$} & & 737 & 51.3 & {$[47.6,54.9]$} & & \\
\hline
\end{tabular}


Table 2 Bivariate associations of physical or sexual IPV in the last 12 months with behavioral and socio-demographic characteristics (Continued)

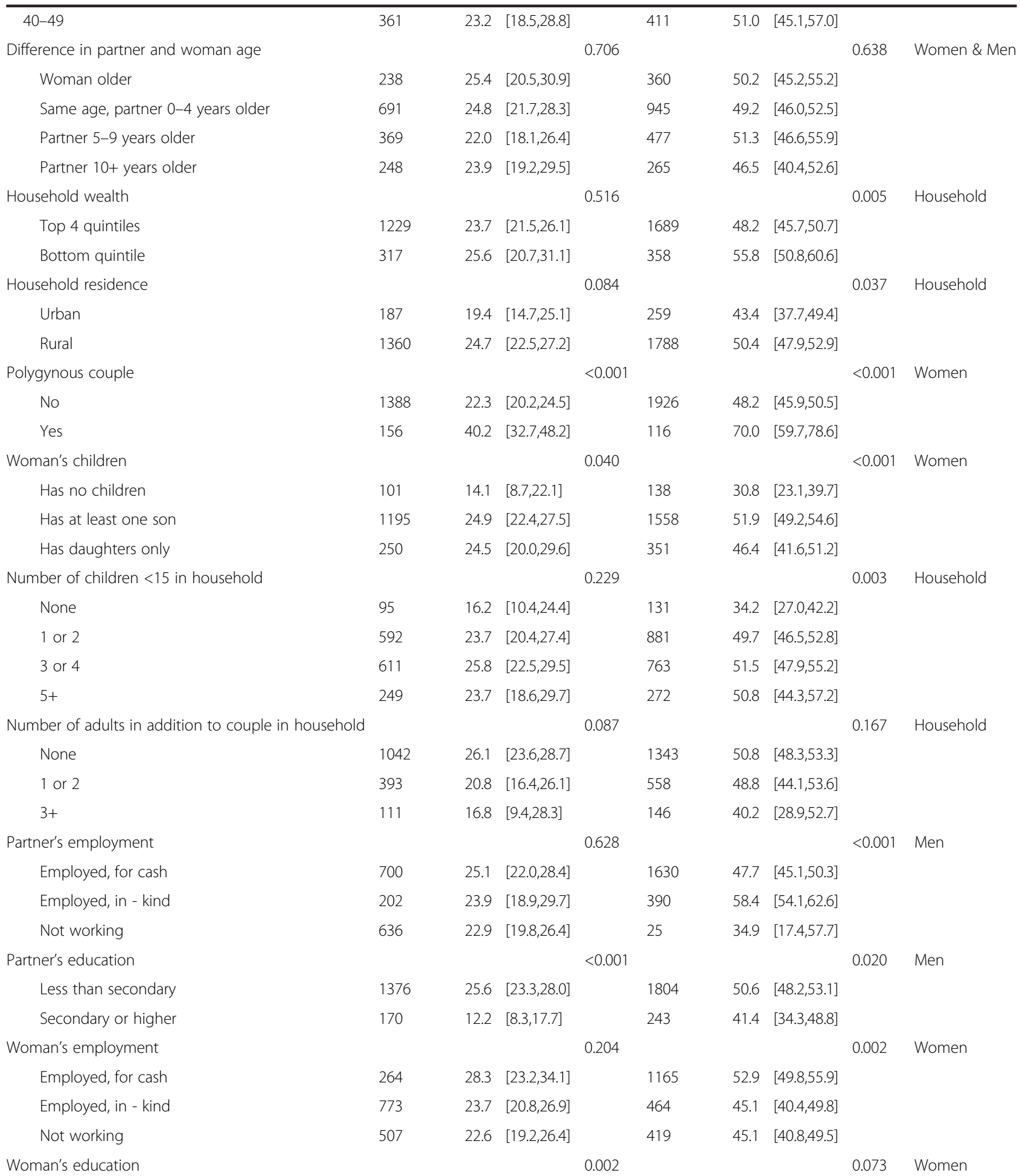


Table 2 Bivariate associations of physical or sexual IPV in the last 12 months with behavioral and socio-demographic characteristics (Continued)

\begin{tabular}{|c|c|c|c|c|c|c|}
\hline No school & 438 & 22.5 & {$[18.9,26.6]$} & 396 & 48.3 & {$[43.1,53.5]$} \\
\hline Primary & 988 & 26.1 & {$[23.5,29.0]$} & 1458 & 50.8 & {$[48.1,53.5]$} \\
\hline Secondary or higher & 121 & 13.2 & {$[8.6,19.6]$} & 193 & 42.1 & {$[35.2,49.2]$} \\
\hline IPV overall ${ }^{\mathrm{a}}$ & 1546 & 24.1 & {$[22.0,26.3]$} & 2047 & 49.5 & {$[47.2,51.8]$} \\
\hline
\end{tabular}

${ }^{a}$ Covariate frequencies may not add to total due to missing responses

associated with IPV across years in our study. The practice of polygyny in Rwanda is illegal, uncommon, and may be falling [32]. In 2005, $12 \%$ of married women were in a polygynous union, and in $2010,8 \%$ of women reported being in polygynous union [9]. Hypothesized links between polygyny and IPV are that the presence of more than two spouses contributes to more marital disagreement [37], and that the practice of polygyny reflects acceptance of male dominance in intimate partnership [38]. The link between having a child and increased risk of IPV among women could reflect that men who act violently toward their spouse/partner are also likely to act violently toward children [39]. Our finding that number of children in the household was not associated with IPV suggests that IPV in the context of having children is not instigated by economic or parenting stressors alone. Other studies found that in households with multiple forms of domestic violence including violence toward children, the level of violence against women sometimes increased if the woman directed aggression or neglect toward the child, or if she intervened in violence toward the children [40].

\section{Communities}

While there is great variability in risk factors for IPV across countries, IPV beliefs and behaviors are commonly associated with IPV incidence [41, 42]. The addition of numerous belief and behavioral risk factors for IPV in the 2010 analysis may be evidence of improved reporting of IPV. Improved self-reporting during the time of this study is expected as a result of new laws and programs. Several laws passed between 1998 and 2008 addressed sexual violence used during the Genocide, the 2003 constitution created gender quotas and promoted gender equality, and the 2008 law on Prevention and Punishment of GBV made domestic violence illegal. To help overcome fears by women victims of IPV that their reports of violence will not be taken seriously, nearly all police stations staff a gender desk with trained, usually female, personnel. In 2009, the Rwanda National Police in partnership with the Ministry of Health and with the technical and financial support of UN agencies, namely UNICEF, UNWOMEN and UNFPA, launched the One Stop Center project that offers free, integrated medical, psycho-social, and legal services to victims of IPV and child abuse. In 2014, Isange One Stop Center Scale Up Project was launched with an aim of establishing this multidisciplinary service in all 44 district hospitals.

Given the complexity of IPV and the mixed evidence in this analysis, the higher incidence of IPV in 2010 may have resulted from both improved self-reporting and increased incidence of IPV due to social disruption. As such, we recommend multiple avenues to address IPV in Rwanda at a social-level. To the extent that prevalent violence against women already existed due to entrenched social, cultural, or historical norms, or has been inflamed by disrupting those norms, we recommend improved legal systems to protect women against violence, and campaigns to reduce acceptance of IPV and to redefine gender roles.

Extending legal protections An alternative to the One Stop Center program is the Abunzi community mediation system [36] which was introduced in 2004 to deal with a backlog of cases in the court system, and has since been formalized with the creation of an Abunzi Secretariat which oversees mediator training and coordination with the Ministry of Justice. Like the gacaca courts, which heard genocide cases, the Abunzi system is a hybrid of traditional and modern methods of conflict resolution, and is perceived by many as more accessible and responsive than legal courts. Each Abunzi committee is comprised of at least 12 members, $30 \%$ of whom are supposed to be women, and serve a local group of villages. While the Abunzi system may present fewer social barriers to victims of IPV than the justice system, many Abunzi committees do not maintain $30 \%+$ women representation, mediations are public, and mediators are often unfamiliar with existing laws and turn to customary laws that may be prejudiced against women [41]. The Abunzi system may be a positive forum for certain IPV cases, especially if the victim is comfortable with the process, and the system is able to support couples to effectively communicate through differences that prevent future violence. However, better support and training of Abunzi mediators is needed to appropriately protect victims of domestic violence according to national law. 
Table 3 Multivariable odds ratios between risk factors and sexual or physical IPV in the last 12 months

\begin{tabular}{|c|c|c|c|c|c|c|}
\hline & \multicolumn{4}{|l|}{2005} & \multicolumn{2}{|l|}{2010} \\
\hline & Full & Reduced & Full & Reduced & Full & Reduced \\
\hline \multicolumn{7}{|l|}{ Beliefs and behaviors } \\
\hline \multicolumn{7}{|c|}{ Emotional violence by partner last 12 months } \\
\hline No & 1.00 & 1.00 & & & Not & Not \\
\hline Yes & $19.0^{* * *}$ & $18.1^{* * *}$ & & & available & available \\
\hline \multicolumn{7}{|c|}{ Woman beat partner unprovoked last 12 months } \\
\hline No & 1.00 & 1.00 & & & Not & Not \\
\hline Yes & $10.8^{*}$ & $12.3^{* *}$ & & & available & available \\
\hline \multicolumn{7}{|c|}{ Woman's father beat mother } \\
\hline No & 1.00 & 1.00 & & & Not & Not \\
\hline Yes & $1.80^{* * *}$ & $1.82^{* * *}$ & & & available & available \\
\hline \multicolumn{7}{|c|}{ Partner consumes alcohol very often } \\
\hline Never or sometimes & 1.00 & 1.00 & & & Not & Not \\
\hline Very often & $3.16^{* * *}$ & $3.13^{* * *}$ & & & available & available \\
\hline \multicolumn{7}{|c|}{ Partner believes a man can beat his wife } \\
\hline 0 reasons & 1.00 & & 1.00 & & 1.00 & 1.00 \\
\hline $1+$ reasons & 1.11 & & 1.12 & & $1.29^{*}$ & $1.30^{*}$ \\
\hline \multicolumn{7}{|c|}{ Woman believes a man can beat his wife } \\
\hline 0 reasons & 1.00 & & 1.00 & & 1.00 & \\
\hline $1+$ reasons & 1.00 & & 1.03 & & $1.35^{* *}$ & $1.36^{* *}$ \\
\hline \multicolumn{7}{|c|}{ Woman involved in her own health decisions } \\
\hline Partner only, other & 1.00 & & 1.00 & & 1.00 & 1.00 \\
\hline Woman involved & 0.80 & & 0.84 & & $0.78^{*}$ & $0.79^{*}$ \\
\hline \multicolumn{7}{|c|}{ Woman involved with decisions about her earnings } \\
\hline Partner only, other & 1.00 & & 1.00 & & 1.00 & 1.00 \\
\hline Woman involved & 1.04 & & 0.93 & & $0.59^{* *}$ & $0.57^{* *}$ \\
\hline No earnings & 0.71 & & 0.64 & & $0.48^{* * *}$ & $0.47^{* * *}$ \\
\hline Not working & 0.75 & & 0.72 & & $0.65^{*}$ & $0.62^{*}$ \\
\hline \multicolumn{7}{|c|}{ Partner had sex with non-wife last 12 months } \\
\hline No & 1.00 & & 1.00 & & 1.00 & 1.00 \\
\hline Yes & 0.94 & & 1.13 & & $2.49^{* * *}$ & $2.52^{* * *}$ \\
\hline \multicolumn{7}{|c|}{ Woman says it is okay to refuse sex } \\
\hline No & 1.00 & & 1.00 & & 1.00 & \\
\hline Yes & 1.05 & & 0.98 & & 0.81 & \\
\hline \multicolumn{7}{|l|}{ Socio-demographics } \\
\hline \multicolumn{7}{|l|}{ Woman's age } \\
\hline $15-19$ & 1.00 & & 1.00 & & 1.00 & \\
\hline $20-29$ & 1.15 & & 1.22 & & 1.47 & \\
\hline $30-39$ & 1.07 & & 1.09 & & 1.62 & \\
\hline $40-49$ & 1.48 & & 1.33 & & 1.89 & \\
\hline \multicolumn{7}{|l|}{ Household wealth } \\
\hline Top 4 quintiles & 1.00 & & 1.00 & & 1.00 & 1.00 \\
\hline Bottom quintile & 0.98 & & 0.99 & & 1.22 & $1.25^{*}$ \\
\hline
\end{tabular}


Table 3 Multivariable odds ratios between risk factors and sexual or physical IPV in the last 12 months (Continued)

\begin{tabular}{|c|c|c|c|c|c|c|}
\hline \multicolumn{7}{|l|}{ Household residence } \\
\hline Urban & 1.00 & & 1.00 & & 1.00 & \\
\hline Rural & 1.44 & & 1.17 & & 1.06 & \\
\hline \multicolumn{7}{|l|}{ Polygynous couple } \\
\hline No & 1.00 & 1.00 & 1.00 & 1.00 & 1.00 & 1.00 \\
\hline Yes & $1.55^{*}$ & $1.51^{*}$ & $2.35^{* * *}$ & $2.41^{* * *}$ & $2.31^{* * *}$ & $2.29 * *$ \\
\hline \multicolumn{7}{|l|}{ Woman's children } \\
\hline Has no children & 1.00 & & 1.00 & 1.00 & 1.00 & 1.00 \\
\hline Has at least one son & 1.95 & & $2.04^{*}$ & $2.04^{*}$ & 1.67 & $2.05^{* *}$ \\
\hline Has daughters only & $2.24^{*}$ & & $2.13^{*}$ & $2.11^{*}$ & $2.09^{*}$ & $2.58^{* * *}$ \\
\hline \multicolumn{7}{|c|}{ Number of children $<15$ in household } \\
\hline None & 1.00 & & 1.00 & & 1.00 & \\
\hline 1 or 2 & 0.98 & & 1.00 & & 1.30 & \\
\hline 3 or 4 & 0.99 & & 1.20 & & 1.23 & \\
\hline $5+$ & 1.04 & & 1.17 & & 1.18 & \\
\hline \multicolumn{7}{|c|}{ Number of adults in addition to couple in household } \\
\hline None & 1.00 & & 1.00 & & 1.00 & \\
\hline 1 or 2 & $0.61^{*}$ & & $0.67^{*}$ & & 0.90 & \\
\hline $3+$ & 0.49 & & 0.47 & & 0.63 & \\
\hline \multicolumn{7}{|l|}{ Partner's employment } \\
\hline Employed, for cash & 1.00 & & 1.00 & & 1.00 & 1.00 \\
\hline Employed, in - kind & 0.77 & & 0.76 & & $1.54^{* * *}$ & $1.58^{* * *}$ \\
\hline Not working & $0.72^{*}$ & & 0.85 & & 0.67 & 0.65 \\
\hline \multicolumn{7}{|l|}{ Partner's education } \\
\hline Less than secondary & 1.00 & 1.00 & 1.00 & 1.00 & 1.00 & \\
\hline Secondary or higher & $0.46^{* *}$ & $0.43^{* *}$ & $0.44^{* *}$ & $0.45^{* *}$ & 0.88 & \\
\hline \multicolumn{7}{|l|}{ Woman's education } \\
\hline No school & 1.00 & & 1.00 & 1.00 & 1.00 & \\
\hline Primary & 1.34 & & $1.38^{*}$ & $1.40^{*}$ & 1.30 & \\
\hline Secondary or higher & 0.85 & & 0.88 & 0.88 & 1.27 & \\
\hline$N(\text { weighted })^{a}$ & 1502 & 1520 & 1527 & 1544 & 2027 & 2029 \\
\hline
\end{tabular}

${ }^{* * *} p<0.001,{ }^{* *} p<0.01,{ }^{*} p<0.5$

a Sample size reduced by missing responses among covariates

Redefining the roles of women and men in society Pressure on men to change their behaviors and perception of themselves as men without well-formed alternative models of masculinity will not lead to sustained reductions in violence $[28,42]$. This is likely true of women in terms of femininity, as well. As such, effective IPV policies and programs require men's participation in redefining masculinity. Although much work has already taken place in Rwanda to redefine gender roles, it has happened relatively recently mostly through top-down approaches [14]. Successes include the 2008 law against gender-based violence which was brought to parliament by four women and four men who effectively fostered buy-in from the mostly male parliament at that time [43]. Other programs to prevent and respond to genderbased violence have been implemented within the Rwanda National Police and the Rwanda Defense Force, and gender quotas have been adopted for UN peace keeping forces [20]. Among the only grassroots initiatives on this issue in Rwanda, however, is the Men's Resource Centre (RWAMREC) which is run by men who advocate for gender equity and promotion of nonviolent ideals of masculinity [20].

Perhaps as a result of atypically top-down approaches, Rwandans overall hold highly inequitable attitudes about gender roles; for example, $61 \%$ of Rwandan men 
agree with the statement "changing diapers, giving kids a bath and feeding kids are the mother's responsibility" [44], and DHSs show increasing rather than decreasing tolerance for IPV. More bottom-up approaches may be needed in Rwanda. Grassroots approaches that have proven successful to shift attitudes about gender and IPV in other African contexts include single-sex group trainings with dialogues [45]. Although RWAMREC sensitizes communities to IPV laws during umaganda, the monthly national day of service, and facilitates dialogues about IPV in umugoroba w'abashakanye evening meetings of five to ten couples [20], further initiatives like these, along with time, may be needed to shift attitudes toward gender roles in Rwanda.

The doubling in self-reported IPV in Rwanda between 2005 and 2010 is deeply concerning, and further investigations of reasons for this increase are urgently needed. This study summarizes trends, correlates, and broad hypotheses for IPV, however, the cross-sectional nature of the DHS does not allow us to draw causal conclusions about predictors or consequences of IPV. Furthermore, measurement of physical and sexual IPV in household surveys is subject to under-reporting due to interviewer traits and difficulty securing privacy in smaller, densely populated homes [46]. We find it unrealistic that privacy was secured in $100 \%$ (2005) and >99 \% (2010) of interviews, and suspect that under-reporting of IPV occurred in both surveys. Finally, the 2010 DHS did not ask about emotional violence, IPV witnessed in childhood, woman's violence against her husband/partner, and alcohol usage, all of which are important risk factors for IPV that could not be tested in our 2010 analysis.

The 2015 DHS was recently completed but not released at the time of this writing, and results from that survey might provide important insight about trends in IPV. Preliminary results of the 2015 DHS indicate continued rapid economic development in Rwanda, which is expected to correlate with a drop in IPV $[12,17]$. We recommend additional research to tease out to what extent-increased selfreports of IPV are due to increased incidence of IPV versus greater empowerment by women to report violence. Researchers should investigate how changes in gender roles in Rwanda, and the unique demographic distribution of women and men in Rwanda, may relate to experiences of IPV. Furthermore, research is needed to evaluate the effectiveness of IPV interventions such as police station gender desks, district hospital Isange One Stop Centers toward reducing incidence of IPV. Concerns about how well Abunzi mediators are able to address IPV should be investigated. Campaigns that involve men and women in redefining gender roles could be an important contribution to the gender equality agenda moving forward in Rwanda, and the effects of these campaigns on IPV and IPV perceptions should be systematically evaluated.

\section{Conclusions}

Rwanda has one of the highest self-reported rates of intimate partner violence against women worldwide, and multiple forms of current or past violence are reported by the same women. Doubling in self-reported violence between 2005 and 2010 coincided with major political and social gains. While the Rwandan health and legal sectors have multiple initiatives to support victims, additional campaigns may be needed to shift public perception and perpetration of intimate partner violence. The impact of these programs, and changes in reported violence, need further investigation.

\section{Competing interests}

WR is overseeing the scale-up of One Stop Center program to all of Rwanda's district hospitals for the Ministry of Health. The authors declare no other competing interests.

\section{Authors' contributions}

All authors conceived this study. Initial literature review was performed by ABB. Analysis was performed by DRT with regular feedback from LM and WR. The text was mainly drafted by DRT and LM. All authors reviewed and approved the final text.

\section{Acknowledgments}

We thank Shafiga Murebwayire, Coordinator of the Isange One Stop Center project, for her insights to the daily experiences of women and men reporting intimate partner violence, and Bethany Hedt-Gauthier and Daniel Corsi for their valuable input about statistical methodologies. We also thank Mara Goldman and Kristin Dunkle for their very helpful reviews and suggestions to improve this manuscript.

\section{Author details}

${ }^{1}$ School of Public Health, College of Medicine and Health Sciences, University of Rwanda, Kigali, Rwanda. ${ }^{2}$ Department of Global Health and Social Medicine, Harvard Medical School, Boston, MA, USA. ${ }^{3}$ Isange One Stop Center Scale up Project, Rwanda National Police, Kigali, Rwanda. ${ }^{4}$ College of Medicine and Health Sciences, University of Rwanda, PO Box 945, Kigali, Rwanda.

Received: 19 February 2015 Accepted: 19 October 2015

Published online: 28 October 2015

\section{References}

1. Campbell JC. Health consequences of intimate partner violence. Lancet. 2002;359:1331-6. doi:10.1016/S0140-6736(02)08336-8.

2. Ellsberg M, Jansen HA, Heise L, Watts CH, Garcia-Moreno C, WHO Multi-country Study on Women's Health and Domestic Violence against Women Study Team. Intimate partner violence and women's physical and mental health in the WHO multi-country study on women's health and domestic violence: an observational study. Lancet. 2008;371:1165-72. doi:10.1016/S0140-6736(08)60522-X.

3. World Health Organization (WHO): Global and regional estimates of violence against women: prevalence and health effects of intimate partner violence and non-partner sexual violence. WHO. 2013. http:// www.who.int/reproductivehealth/publications/violence/9789241564625/ en/. Accessed 2 Feb 2015.

4. International ICF. Demographic and health surveys methodology questionnaires: Household, woman's, and man's. MEASURE DHS phase III. Calverton, MD: ICF International; 2011.

5. World Health Organization (WHO). WHO multi-country study on women's health and life events. Questionnaire v9.9. Geneva: WHO; 2005.

6. Reproductive health surveys: Global Health Data Exchange, Seattle. 2014. http://ghdx.healthdata.org/series/reproductive-health-survey-rhs. Accessed 26 Sept 2014.

7. Johnson H, Ollus N, Nevala S. Violence against women: An international perspective. New York: Springer; 2008. 
8. Institut National de la Statistique du Rwanda (INSR), ORC Macro. Rwanda demographic and health survey 2005. Calverton, MD: INSR and ORC Macro; 2006.

9. National Institute of Statistics of Rwanda (NISR) [Rwanda], Ministry of Health (MOH) [Rwanda], ICF International. Rwanda demographic and health survey 2010. Calverton, MD: NISR, MOH, and ICF International; 2012.

10. Devlin C, Elgie R. The effect of increased women's representation in parliament: The case of Rwanda. Parliam Aff. 2008;61:237-54. doi:10.1093/pa/gsn007.

11. Women's Commission for Refugee Women and Children (WCRWC). Rwanda's women and children: The long road to reconciliation. New York: WCRWC; 1997.

12. Bowman CG: Theories of domestic violence in the African context. Cornell Law Faculty Publications. 2003. http://scholarship.law.cornell.edu/facpub/ 131. Accessed 18 Feb 2015.

13. Burrill E, Roberts R, Thornberry E. Domestic violence and the law in colonial and postcolonial Africa. Athens, OH: Ohio University Press; 2010.

14. Wallace C, Haerpfer C, Abbott P. Women in Rwandan politics and society. Int J Sociol Fam. 2008;38:111-25. doi:10.2753/IJS0020-7659380406.

15. Sugarman DB, Frankel SL. Patriarchal ideology and wife assault: A metaanalytic review. J Fam Violence. 1996;11:13-40.

16. Kohlman S, Baig A, Balice G, DiRubbo C, Plancencia L, Skale K, et al. Contribution of media to the normalization and perpetuation of domestic violence. Austin J Psychiatry Behav Sci. 2014;1:e6.

17. Uthman OA, Lawoko S, Moradi T. Factors associated with attitudes towards intimate partner violence against women: a comparative analysis of 17 sub-Saharan countries. BMC Int Health Hum Rights. 2009;9:14. doi:10.1186/1472-698X-9-14

18. Burnet JE: Women have found respect: gender quotas, symbolic representation, and female empowerment in Rwanda. Politics \& Gender. 2011; doi: 10.1017/S1743923X11000250.

19. Slegh H, Richters A. Masculinity and gender-based violence in Rwanda: The potential contribution of community-based strategies to make change. In: Freedman J, editor. Engaging men in the fight against gender violence: Case studies from Africa. New York: Palgrave Macmillan; 2012

20. Carlson K, Randell S. Gender and development: Working with men for gender equality in Rwanda. Agenda. 2013;27:114-25. doi:10.1080/10130950.2013.796075.

21. Islam TM, Tareque MI, Tiedt AD, Hoque N. The intergenerational transmission of intimate partner violence in Bangladesh. Glob Health Action. 2014;7:23591. doi:10.3402/gha.v7.23591.

22. Abeya SG, Afework MF, Yalew AW. Intimate partner violence against women in western Ethiopia: prevalence, patterns, and associated factors. BMC Public Health. 2011;11:913. doi:10.1186/1471-2458-11-913.

23. Rada C. Violence against women by male partners and against children within the family: prevalence, associated factors, and intergenerational transmission in Romania, a cross-sectional study. BMC Public Health. 2014;14:129. doi:10.1186/1471-2458-14-129.

24. Vieira EM, Perdona Gda S, Santos MA. Factors associated with intimate partner physical violence among health service users. Rev Saude Publica. 2011:45:730-7.

25. Rani M, Bonu S. Attitudes toward wife beating: a cross-country study in Asia J Interpers Violence. 2009;24:1371-97. doi:10.1177/0886260508322182.

26. Zacarias AE, Macassa G, Svanstrom L, Soares JJF, Antai D. Intimate partner violence against women in Maputo city, Mozambique. BMC Int Health Hum Rights. 2012;12:35. doi:10.1186/1472-698X-12-35.

27. Moore TM, Stuart GL, Meehan JC, Rhatigan DL, Hellmuth JC, Keen SM. Drug abuse and aggression between intimate partners: a meta-analytic review. Clin Psychol Rev. 2008;28:247-74.

28. Jewkes R. Intimate partner violence: causes and prevention. Lancet. 2002:359:1423-9.

29. Makayoto LA, Omolo J, Kamweya AM, Harder VS, Mutai J. Prevalence and associated factors of intimate partner violence among pregnant women attending Kisumu District Hospital, Kenya. Matern Child Health J. 2013:17:441-7. doi:10.1007/s10995-012-1015-x.

30. Zawacki T, Norris J, George WH, Abbey A, Martell J, Stoner SA, et al. Explicating alcohol's role in acquaintance sexual assault: complementary perspectives and convergent findings. Alcohol Clin Exp Res. 2005;29:263-9.

31. Rocca CH, Rathod S, Falle T, Pande RP, Krishnan S. Challenging assumptions about womens empowerment: social and economic resources and domestic violence among young married women in urban South India. Int J Epidemiol. 2009;38:577-85. doi:10.1093/ije/dyn226.
32. African Centre for Gender and Social Development: Violence against women in Africa: a situational analysis. United Nations Economic Commission for Africa. 2010. http://www1.uneca.org/Portals/awro/ Publications/21VAW\%20in\%20Africa-A\%20situational\%20analysis.pdf. Accessed 2 Feb 2015.

33. Martin SL, Tsui AO, Maitra K, Marinshaw R. Domestic violence in northern India. Am J Epidemiol. 1999;150:417-26.

34. Boyle MH, Georgiades K, Cullen J, Racine Y. Community influences on intimate partner violence in India: women's education, attitudes towards mistreatment and standards of living. Soc Sci Med. 2009;69:691-7. doi:10.1016/j.socscimed.2009.06.039.

35. Krishnan S, Rocca CH, Hubbard AE, Subbiah K, Edmeades J, Padian NS. Do changes in spousal employment status lead to domestic violence? Insights from a prospective study in Bangalore, India. Soc Sci Med. 2010;70:136-43. doi:10.1016/j.socscimed.2009.09.026

36. Mutisi M. Local conflict resolution in Rwanda: the case of abunzi mediators. In: Kasaija P, Rothbart D, Tsuma W, editors. Integrating Traditional and Modern Conflict Resolution Experiences from selected cases in Eastern and the Horn of Africa. Durban, South Africa: Accord; 2012. p. 41-74.

37. Lawoko S, Dalal K, Jiayou $L$, Jansson B. Social inequalities in intimate partner violence: A study of women in Kenya. Violence Vict. 2007;22:773-84. doi:10.1891/088667007782793101.

38. Strauss G. Is polygamy inherently unequal? Ethics. 2012;122:516-44. doi:10.1086/664754.

39. O'Leary DK, Smith Slep AM, O'Leary SG. Co-occurrence of partner and parent Aggression: Research and treatment implications. Behav Ther. 2000;31:631-48. doi:10.1016/50005-7894(00)80035-0.

40. Jouriles EN, McDonald R, Slep AMS, Heyman RE, Garrido E. Child abuse in the context of domestic violence: Prevalence, explanations, and practice implications. Violence Vict. 2008;23:221-35. doi:10.1891/0886-6708.23.2.221.

41. Knox A: Abunzi capacity assessment. Rwanda LAND Project. 2012. http://rwandapedia.rw/content/abunzi-reports. Accessed 2 Feb 2015

42. Sideris T. "You have to change and you don't know how!": Contesting what it means to be a man in a rural area of South Africa. Afr Stud. 2004;63:29-49. doi:10.1080/0002018042000226148.

43. Powley E, Pearson E. Gender is society: Inclusive lawmaking in Rwanda's parliament. Critical Half. 2007:5:15-9.

44. Barker G, Contreras JM, Heilman B, Singh AK, Verma RK, Nascimento M: Evolving men: Initial results from the International Men and Gender Equality Survey (IMAGES). 2011. http://promundoglobal.org/wp-content/uploads/ 2014/12/Evolving-Men-Initial-Results-from-IMAGES.pdf. Accessed 15 Jul 2015

45. Seedat M, Van Niekerk A, Jewkes R, Suffla S, Ratele K. Health in South Africa 5 Violence and injuries in South Africa: prioritising an agenda for prevention. Lancet. 2009;374:1011-22

46. Ellsberg M, Heise L, Pena R, Agurto S, Winkvist A. Researching domestic violence against women:methodological and ethical considerations. Stud Fam Plann. 2001.doi:10.1111/j.1728-4465.2001.00001.x.

\section{Submit your next manuscript to BioMed Central and take full advantage of:}

- Convenient online submission

- Thorough peer review

- No space constraints or color figure charges

- Immediate publication on acceptance

- Inclusion in PubMed, CAS, Scopus and Google Scholar

- Research which is freely available for redistribution 